\title{
Memory impairment associated with chronic hypoxia
}

\author{
FELICIA A HUPPERT \\ From the University Department of Experimental Psychology; Cambridge
}

A B STRACT A series of mental tests was administered to a group of patients who were chronically hypoxic as a result of chronic obstructive lung disease. The oxygen tension from arterialised ear lobe blood samples was correlated with scores on the mental tests. Hypoxia had a significant effect on the results of memory tests but not on the results of other tests of mental function. The same pattern of results has been reported in hypoxic animals. This finding has implications for the treatment of chronic hypoxia-including the very mild hypoxia that is relatively common in the elderly; if this were treated possibly memory impairment would no longer be an inevitable accompaniment of aging.

It is well known that acute hypoxia such as that which results from a rapid ascent to a high altitude is associated with mental confusion. Even the mild hypoxia resulting from an ascent to 1500 metres has been shown to reduce the ability to perform new tasks. ' Nevertheless, the extent to which mental function is affected by the chronic hypoxia that is common in patients with obstructive lung disease is not clear. Some degree of physiological compensation does take place, minimising any cerebral effects of oxygen lack ${ }^{2}$; but an investigation recently undertaken in rats showed that chronic hypoxia impaired memory, though it did not affect speed of performance (K Duggan et al, paper presented to meeting of Australian Society for the Study of Animal Behaviour, 1981).

Accordingly we thought that a detailed examination of the relation between chronic hypoxia and mental function in man should be undertaken. Evidence of impaired mental function would have important practical implications. If normal physiological compensation is insufficient to combat the cerebral effects of hypoxia, this might encourage the more widespread use of domiciliary oxygen treatment, which has already been shown to improve longevity in severely hypoxic patients. ${ }^{3}$

The aims of the present investigation were twofold: firstly, to determine whether chronic hypoxia is associated with impaired mental functioning in man and, secondly, to determine whether certain mental functions are more susceptible than others. Since chronically hypoxic patients tend also to take particular forms of medication, we thought that an experimental design which compared their performance on mental tests with that of a control group not taking the medication would make the results difficult to interpret. We therefore

Address for reprint requests: University Department of Experimental Psychology, Downing Street. Cambridge CB2 3EB. decided to use a correlational approach relating the degree of hypoxia to scores on mental tests in a group of hypoxic patients.

\section{Methods}

The group comprised 11 outpatients (eight men, three women) who regularly attended the chest clinic at the Royal Canberra Hospital. They ranged in age from 43 to 77 (mean 60.6) years and came mostly from a workingclass background. Ten were diagnosed as having chronic bronchitis or emphysema. A woman aged 43 had fibrosing alveolitis.

Testing took place in the respiratory laboratory at the Royal Canberra Hospital. Each patient was tested on a single occasion, the session lasting $1-1 \frac{1}{2}$ hours. We used specially designed mental tests which we had previously shown to be highly sensitive to small differences between and within subjects. ${ }^{47}$ The following tests were administered.

Simple reaction time The patients' task was to press a button as quickly as possible when a flash of light appeared on a screen. They were given a verbal warning signal and the flash appeared $0 \cdot 5-2 \cdot 0$ seconds later. Trials were continued until a stable level of performance was reached. The median speed of the last 10 trials was of recorded.

Decision making The test materials were 40 slides of $\mathcal{N}$ line drawings of familiar objects, plants, and animals. Half the drawings had a red outline, half a black outline. In half the trials patients had to make a simple decision about the colour of the outline by depressing the $\stackrel{\mathbb{D}}{\mathscr{D}}$ appropriate "yes" or "no" button in response to the : question "Is it red?" In the rest of the trials they had to make the more complex decision about category by depressing the appropriate button in response to the question "Is it living?" The questions were asked in a 
random sequence. Each trial began with a question, then a slide appeared for one second and the time between the appearance of the slide and the subject's response was recorded on a millisecond timer. At the end of the 40 trials patients were given an unexpected memory test. They were first asked to recall as many of the pictures as possible. Then they were given a recognition test in which the 40 original slides were randomly interspersed among 40 new slides and the task was to identify the ones which had been shown previously. (This is referred to as incidental memory below.)

Memory for words Twenty common words were presented on slides for one second each and the patient was instructed to remember them. After one minute of conversation subjects were asked to recall as many of the words as they could remember and were subsequently required to recognise the 20 original words randomly interspersed among 20 new words (this is referred to as intentional memory below). The recognition score was the percentage of correct true-positive and true-negative responses.

Memory for pictures Twenty slides of complex coloured pictures photographed from magazines (for example, scenery, people) were presented for one second each and the patient was instructed to remember them. Recall and recognition were tested as for words.

Word fluency Patients were asked to say aloud as many words as they could in one minute beginning with a designated letter of the alphabet. There were two trials, one using $\mathrm{C}$ and the other $\mathrm{S}$ as the initial letters. The mean number of words produced was recorded.

Conflict task A sheet of paper was presented containing 42 words arranged in two columns. The words were "red," "green," and "blue," which appeared in random sequence and were coloured in a conflicting colour-for example, the word "red" written in blue ink. This is known as the Stroop test, after its inventor. ${ }^{8}$ The patient's task was to name the colour in which each word was written-that is, to ignore the conflicting information produced by reading the word. The time taken to complete the list was recorded.

During the course of the session a respiratory technician took samples of arterialised blood from the ear lobes to measure blood gas tensions. Two samples, separated by 10 minutes, were taken from each patient, one from each ear lobe. This provided a check on the reliability of the measurement. The blood samples were collected in heparinised tubes and analysed in an automatic blood gas analyser.

\section{Results}

The mean and range of each measurement is presented in the table. Errors in recall, decision making, and the conflict task were very rare, and therefore not analysed.

Overall performance of the group on these tests accords well with the pattern of performance found for other groups ${ }^{5-7} 9$ - that is: $(a)$ recall is more difficult than recognition; $(b)$ words are more difficult to remember than pictures; $(c)$ incidental memory tests are more difficult than intentional memory tests; $(d)$ decisions about category (living versus manmade) take longer than decisions about physical features (colour); and $(e)$ items which originally required a decision about category are remembered better than those which originally required a decision about physical features (mean percentage of correct recognition responses is $56 \cdot 5$ (range $35-80$ ) after the colour decision and 73.0 (range 55-90) after the category decision).

The performance of the hypoxic group on four of the cognitive tests can be compared directly with norms obtained on a sample of 30 unselected elderly community residents (mean age 68.9 years, range 60-83) who attended the Cambridge university psychology laboratory for testing ( $\mathrm{F}$ Huppert, unpublished observations). Test scores for this group were as follows: incidental recall $21 \%$ (range $5-38 \%$ ); incidental recognition $75 \%$ (range 50-93\%); word fluency 17 words/min (range 4-41); conflict task 51 seconds (range 30-87).

For technical reasons, group performance on the remaining tests cannot be compared directly (for example, for the unselected elderly group reaction time was measured by means of a voice key rather than a button press). On every test where direct comparisons could be made, however, the mean performance of the hypoxic group (table 1) was below that of the comparison group despite the fact that the comparison group was considerably older and was unselected with regard to general health.

Results of the blood gas analysis for the hypoxic

Table 1 Mean and range of cognitive test scores of a group of patients with chronic hypoxia

\begin{tabular}{|c|c|c|c|c|c|c|c|c|c|c|c|}
\hline & \multicolumn{6}{|c|}{ Memory (\% correct) } & \multicolumn{3}{|c|}{ Mental speed } & \multirow{4}{*}{$\begin{array}{l}\text { Wordfluency } \\
\text { (words/min) }\end{array}$} & \multirow{4}{*}{$\begin{array}{l}\text { Conflict task } \\
\text { (s) }\end{array}$} \\
\hline & \multicolumn{4}{|c|}{ Intentional memory } & \multicolumn{2}{|c|}{ Incidental memory } & \multicolumn{3}{|c|}{ Reaction time (ms) } & & \\
\hline & \multicolumn{2}{|l|}{ Recall } & \multicolumn{2}{|c|}{ Recognition } & \multirow[t]{2}{*}{ Recall } & \multirow[t]{2}{*}{ Recognition } & \multirow[t]{2}{*}{ Simple } & \multirow[t]{2}{*}{ Colour decision } & \multirow[t]{2}{*}{ Calegorydecision } & & \\
\hline & Pictures & Words & Pictures & Words & & & & & & & \\
\hline Mean & 46 & 32 & 90 & 76 & 20 & $\begin{array}{l}65 \\
45-85\end{array}$ & 153 & 466 & 662 & 16 & 57 \\
\hline Range & $25-70$ & $15-40$ & $75-100$ & $65-88$ & $10-32.5$ & $45-85$ & $132-175$ & $400-561$ & $555-850$ & $9-23$ & $40-105$ \\
\hline
\end{tabular}


Table 2 Results of blood gas analysis in hypoxic patients

\begin{tabular}{lllll}
\hline & $\begin{array}{l}\mathrm{PO}_{2} \\
(\mathrm{kPa})\end{array}$ & $\begin{array}{l}\mathrm{PCO}_{2} \\
(\mathrm{kPa})\end{array}$ & $\begin{array}{l}\mathrm{Hb} \\
(\mathrm{g} / \mathrm{dl})\end{array}$ & $\begin{array}{l}\text { Saturation } \\
(\%)\end{array}$ \\
\cline { 2 - 4 } & $7 \cdot 9$ & $5 \cdot 4$ & $15 \cdot 4$ & $88 \cdot 8$ \\
Rean & $5 \cdot 8-10 \cdot 3$ & $4 \cdot 6-7 \cdot 5$ & $11 \cdot 7-17.9$ & $\begin{array}{l}77 \cdot 9-94 \cdot 5 \\
\text { Range }\end{array}$ \\
\hline Conversion: & SI to traditional units-Blood gases: $1 \mathrm{kPa}=7 \cdot 5 \mathrm{~mm} \mathrm{Hg}$.
\end{tabular}

patients are shown in table 2 . All samples were less than 95\% saturated, confirming that the patients were hypoxic, although two of them were only marginally so $\left(\mathrm{Po}_{2} \mathrm{10} \cdot 3\right.$ and $9.7 \mathrm{kPa}$, saturation $94.5 \%$ ). On the other hand, with the exception of one patient whose $\mathrm{PCO}_{2}$ was $7.5 \mathrm{kPa}$ (saturation $77.9 \%$ ) the $\mathrm{PCO}_{2}$ of the group was very close to the normal range, as was the haemoglobin concentration.

The relation between hypoxia and scores on the mental tests was examined by calculating Pearson productmoment correlations. Age was partialled out of these correlations because of the relatively wide range and the fact that age is known to be associated with changes in both $\mathrm{PO}_{2}$ and test performance. An interesting pattern of results emerged. There was no significant relationship between $\mathrm{PO}_{2}$ and any measure of mental speed, but there was a signficant relationship between $\mathrm{PO}_{2}$ and memory. This was seen only on the most difficult tests of memory-namely, memory for incidentally learnt material. There was a correlation of $0.82(\mathrm{p}=0.025)$ between $\mathrm{PO}_{2}$ and recall, and a correlation of $0.75(\mathrm{p}=$ 0.05 ) between $\mathrm{Po}_{2}$ and recognition of drawings which had required a category decision. For drawings which had required a simple decision about colour the relationship fell short of significance.

\section{Discussion}

The results of the investigation suggest that in man chronic hypoxia is associated with impairment of some aspects of mental function. Memory impairment appears to be implicated but possibly not speed of performance. This finding parallels results recently obtained in a study of rats which were housed in a low-oxygen environment. When they were compared with a control group, their motor activity was normal but hypoxic animals showed a deficit in maze learning and retention (K Duggan et al, paper presented to meeting of Australian Society for the Study of Animal Behaviour, 1981).

Most of the remembering which we do in everyday life is of the incidental type: that is, we recall or recognise objects, items, or events which we made no special effort to memorise. The evidence for a hypoxia-related deficit in incidental memory suggets that physiological compensation for the cerebral effects of chronic hypoxia may be incomplete. It would therefore be clinically useful to establish whether this cognitive deficit is permanent, reflecting hypoxic damage to brain structures, or whether it can be reversed by appropriate treatment such as oxygen therapy.

This work may also have implications for research on aging. Some degree of memory impairment is common in normal (non-demented) elderly people. Moreover, in some elderly people various vascular and respiratory changes combine to produce very mild, chronic hypoxia. To what extent is the memory impairment related to the hypoxia or, more generally, to cardiorespiratory insufficiency? Finally, we may begin to question whether cognitive impairment and physiological insufficiency are "normal" in the elderly-that is, the inevitable accompaniments of the normal aging process. Just as raised blood pressure, once regarded as "normal" in the elderly, is now being actively treated or prevented, it is worth considering whether other aspects of physiological insufficiency besides impaired cognition may be reversed or prevented in older people.

I wish to thank Professor Richard Mark (behavioural biology) and Dr Michael Denborough (clinical science), in whose departments I held a joint visiting fellowship at the Australian National University in 1980. I am particuarly grateful to Dr Stephen Nogrady and his staff at the respiratory laboratory of the Royal Canberra Hospital for the provision of patients and facilities that made this work possible. The statistical help of Judy Frauenfelder is acknowledged with gratitude.

\section{References}

' Denison DM, Ledwith F, Poulton EC. Complex reaction times at simulated cabin altitudes of 5000 feet and 8000 feet. Aerospace Medicine 1966;37:1010-3

2 Robin ED. Of men and mitochondria: coping with hypoxic dysoxia. Annu Rev Respir Dis 1981;22:517-31.

${ }^{3}$ Medical Research Council Working Party. Long-term domiciliary oxygen therapy in chronic hypoxic cor pulmonale complicating chronic bronchitis and emphysema. Lancet $1981 ; \mathrm{i}: 681-5$

${ }^{4}$ Huppert FA. Does mental function decline with age? Geriatric Medicine 1982;12:32-7.

5 Thompson P, Huppert FA. Problems in the development of measures to test performance in adult epileptics. in: Kling B, Stores G, Meinardi H, eds. Epilepsy and behaviour' 79. The Netherlands: Swets and Zeitlinger, 1980.

${ }^{6}$ Thompson P, Huppert FA. Trimble M. Phenytoin and cognitive function: effects on normal volunteers and implications for epilepsy. B J Clin Psychol 1981;20:155-62.

${ }^{7}$ Tucker A, Huppert FA, Petch M. Does digoxin impair cognitive functioning? In: Molloy M, Stanley GV, Walsh KW eds. Brain impairment: proceedings of the 1979 brain impairment workshop. University of Melbourne: Neuropsychology Group. 1980:170-82.

${ }^{8}$ Stroop JR. Studies of interference in serial verbal reactions. $J$ Exp Psychol 1935;18:643-61.

${ }^{9}$ Craik FIM, Tulving E. Depth of processing and the retention of words in episodic memory. $J$ Exp Psychol [Gen] 1975; 104:268-94. 